TRADE NEWS FOCUS

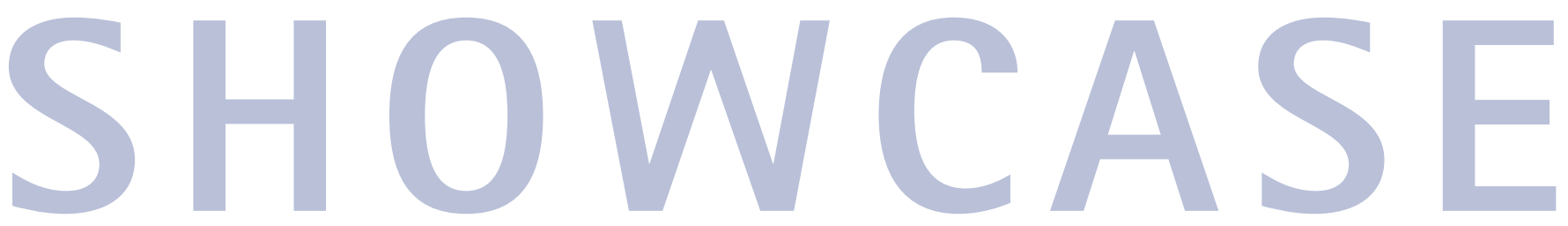

\section{Dental Showcase}

This year's Dental Showcase will be held in Hall 4 of the NEC in Birmingham, on 20-22 November. Opening hours are Thursday 20th: 10am - 6pm, Friday 21st: 10am $6 \mathrm{pm}$ and Saturday 22nd: 10am - $5 \mathrm{pm}$. The venue is easily accessible by road or public transport and for more information contact www.dentalshowcase.com.

\section{Full range}

DB Dental Equipment Ltd on Stand P15 will be exhibiting the latest technology in benchtop washing / disinfecting machines and Optidents' Sterilox Generator, an answer to bio-film removal.

The company will also be announcing their new appointment as A-dec agents.

The stand will also feature the Panoura Panoramic X-ray unit. For further information contact 01484 401015.

Reader response number 55

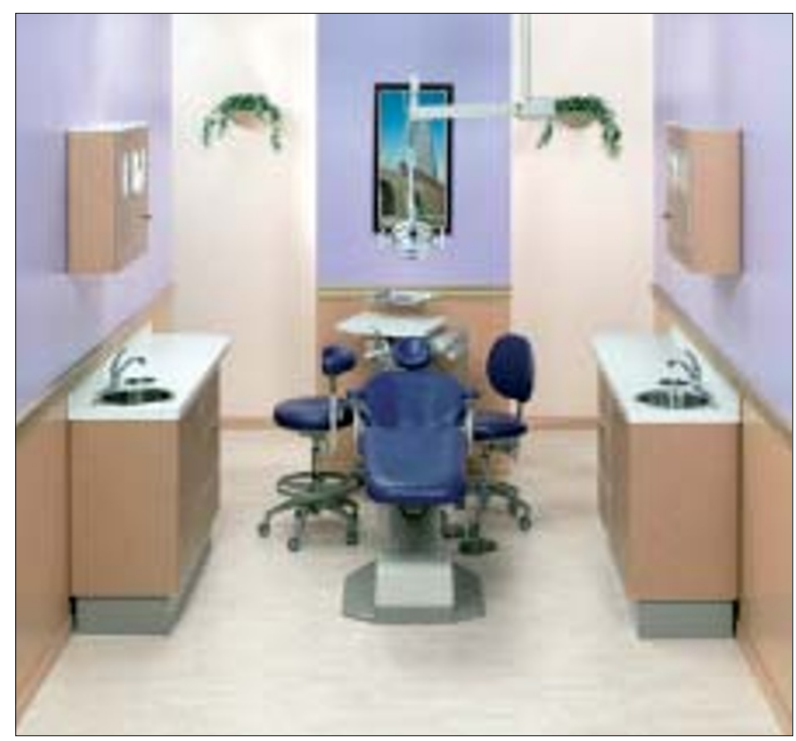

